\begin{tabular}{c} 
International Journal of Engineering \& Technology, $7(3.36)(2018)$ 167-169 \\
International Journal of Engineering \& Technology \\
WPC \\
Website: www.sciencepubco.com/index.php/IJET \\
Research paper \\
\hline
\end{tabular}

\title{
Various Techniques on Retrofitting for Earthquake Hazard Mitigation
}

\author{
Choo Kok Wah ${ }^{1 *}$, Rozana Zakaria ${ }^{1}$, Azlan Adnan ${ }^{1}$, Leong Wai Yie ${ }^{2}$ \\ ${ }^{1}$ Universiti Teknologi Malaysia, Malaysia \\ .$^{2}$ MAHSA University, Malaysia \\ *Corresponding author E-mail: chookwah@hotmail.com
}

\begin{abstract}
Seismic tremors are a sudden vibration or trembling in the Earth that can be felt more than a few hundreds of kilometers. Quakes can twist the ground, making structures and non-structures crumple. Lives might be lost because of building deformation. Malaysia is a nation with low seismic movement. Be that as it may, Malaysia is surrounded by Philippines and Indonesia, which is two of the most seismically dynamic nations and certain level of surface waves, could be felt in our nation. Seismic tremor occasions have turned out to be more regular in this area. Seismic zone mapping for school located in Malaysia particularly in Johor Bahru can assist engineers to predict earthquake risk in building planning. Johor Bahru is situated in southern of peninsular Malaysia and is one of the urban areas with high population. School structures are considered as an essential structure since it contains a high numbers of pupils and teacher most of the time. The seismic zone mapping can recognize high possibly dangerous quake influenced area and essential risk mitigation method can be prepared. The seismic zone mapping not just ready to give designer to recognize region of higher earthquake risk but it can also be a good reference for future seismic safe building advancement.
\end{abstract}

Keywords: Earthquake; Hazard Mitigation; Johor Bahru; Retrofitting; School.

\section{Introduction}

Seismic tremor can cause earth surface to move and cause loss of living spot and lives. Structures are not intended to take this seismic tremor may endure serious damage. Typically, the earth structures in Malaysia region are not intended to assimilate and study seismic waves. These structures are just intended to provide resistant for static load and not dynamic load. High extents of seismic waves will destroy the important building structure. The aim of this research is to propose a seismic zone mapping in Johor Bahru for earthquake mitigation. This seismic zone mapping can assist engineers on assessing the precautionary measures should have been taken while considering earthquake risks in building planning in the future. Other than that, the data accessible in the seismic zone mapping for Johor Bahru Region can be used for creating tremor safe building later on. This seismic zone mapping can recognize territories which are profoundly defenseless against seismic dangers. For structures which are possibly risky, point by point investigation can be completed by utilizing detailed programming. In order to gets the earthquake loading for this detailed study, the NERA program which is capable of generating microzonation data will be used to produce Time History function $(\mathrm{TH})$ and Response Spectrum function (RS). This function will be used as input data for finite element analysis (FEA). The finite elements structural analysis software used is SAP 2000. It will identify the values of axial force, shear force and moment generated from the combination of earthquake forces. These values will then be used to study and compare with the actual structural capacity. Based on comparison, the critical structures can then be identified. Subsequently, the earthquake design parameters can be proposed to cater for seismic loading. An actual school project was selected to carry out the analysis to find out the earthquake design parameter for school building.

\section{Research background}

Malaysia has always been considered and categorized as low seismic region. But the neighbouring countries including Philippines and Indonesia are amongst the two (2) most seismic affected countries. The earthquakes occurrence is frequent. The regional location and close proximity of these two neighbouring countries have make Malaysia liable to be affected by earthquakes [1]. As such, the predicted issues related to earthquakes ought to be handled. There are several issues anticipated to be justified in this catastrophe phenomenon. First, areas and regions to be affected by earthquake occurrence have to be alerted and investigated. If the construction and building is not resisted to earthquakes loading, the earthquakes will result the building shaking and collapse. During the earthquake, the structure will be thrown backward and forward, and up and down. All structure systems will be affected and subjected to hundreds of displacements. In general, the extra inertia forces are the result of movement from the mass and acceleration. Similarly, all actual systems had the potential to have an infinite variety of displacements. The mass analysis of a structural system can be accurately estimated at the nodes. For linear elastic structures, the stiffness properties of the members, with the aid of experimental data, can be approximated with a high degree of confidence [2-5]. However, the dynamic loading, energy dissipation properties and boundary (foundation) conditions for many structures are difficult to estimate. This is always true for the cases of seismic input or wind loads. 


\section{Methodology}
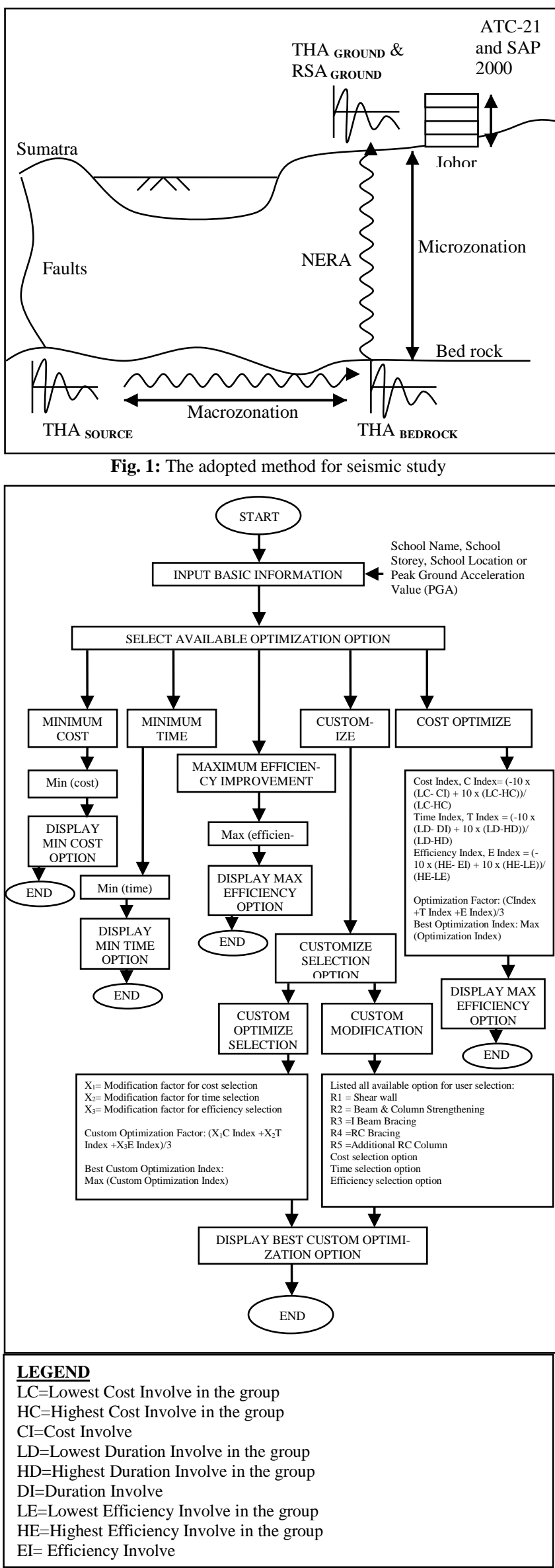

Fig. 2: Cost Optimization Model
In order to evaluate the potential hazard effect to the building's structure due to excessive seismic loading, a literature review was carried out. Earthquake effects on the building structure vary from site to site and mostly depend on the site location, structure material, foundations and building configuration. Engineers need more earthquake related knowledge to understand all the vital information that is much needed in designing the earthquake resistant building. Figure 1 shows the methods adopted to conduct the study. For the purpose of this study, borehole data for various locations in Johor Bahru was collected and used in the microzonation analysis. By applying NERA software to perform the microzonation analysis, the Time History function and Response Spectrum function were obtained. Both functions were used as earthquake loading in finite element analysis. From the Response Spectrum data we obtained Peak Ground Acceleration (PGA) value and by using the PGA value, seismic zone mapping for Johor Bahru District was prepared. A total of 136 soil investigation reports from deep boring borehole were used in the analysis. The soil investigation reports are located in 52 different school locations in Johor Bahru District. These 52 school locations covered a broad region of Johor Bahru District. Finite elements structural analysis software named SAP 2000 was used to analyse the standard fourstorey school building by loading it with additional seismic loading. From the analysis result we acquired moment, shear force and axial load. These loads were compared to the actual structural loading of the building. From the comparison, the additional loads generated in critical structural members were identified. The design engineer is able to take precautions by considering and adding the earthquake loading into the new structure design. Figure 2 shows the Cost Optimization Model use in the study.

\section{Analysis and results}

There are a variety of methods on structural retrofitting. The retrofitting approach can be conducted by way of strengthening the overstressed members, decreasing the pressure distribution and decreasing the seismic demands. To impose the retrofitting approach on the building, the proposed techniques must be suitable and appropriate to the structural deficiencies. When the structural evaluator commented on the lacking of stiffness of the building structure, a more feasible retrofitting method should be used to amplify the structural elements dimensions. It can be solved by inserting with greater structural elements. The common retrofitting techniques will be presented below to understand the uniqueness of the methods [6-9]. The seismic environment of region surrounding low risk zones like Malaysia is differ very much from the area that are in high risk seismic zones [10]. The above research also covers the modeling of distance earthquake and local earthquake risk in Johor Bahru region.

1) Adding additional structural elements. The needs of inserting structural factors are to decrease the force dispensed in every issue (by decreasing the span of structural elements). Inserting new structural elements will extend the structural stiffness of the ordinary structure. To insert the new structural elements, the following standards need to be considered. An accurate detailing needs to be furnished in the connection areas, such as beam-column joint, beam-foundation connection, and column-foundation connection. The structural dimensions and substances properties have to be equal (not a compulsory) to the previous structural factors to grant proper forces distribution, e.g. the dimension of the new column should be the same with the previous one. During development process, the transient help may additionally be considered in the new structural elements.

2) Adding additional horizontal and vertical seismic belts (iron wire mesh) in masonry building. The iron wire mesh is usually carried out to improve the masonry walls. It is commonly applied on the place of beam and column, and crossly utilized at the aspect portal of buildings. The wire mesh is utilized at both the floor of 
masonry and the wire mesh is additionally anchored to hold the role and integration

3) Method of jacketing the structural elements for RC elements (Beam and Column). The idea of concrete jacketing is an addition of thick layer of reinforced concrete in the form of a jacket surrounding the present structural elements (usually columns). Jacketing will improve the flexural strength, ductility and shear energy of the structural elements.

4) Method of strengthening roof trusses and improving roof diaphragms. In strengthening the roof trusses, an addition of diagonal truss connecting two adjacent roof trusses will increase the stiffness of the roof diaphragm system. Moreover, including the diagonal bracing in the equal level of beam will additionally amplify the stiffness of the roof diaphragms.

5) Method of strengthening concrete diaphragm and it flexural capacity. The deficiencies discovered in the concrete diaphragm are insufficient in-plane shear capacity of the concrete diaphragm and insufficient flexural capacity. In strengthening shear capacity, covering the current concrete diaphragm with new strengthened concrete topping slab and lowering the shear through imparting supplemental vertical-resisting factors will enhance the capacity. In strengthening the flexural capacity, casting a new chord member critical with the slab after putting off the edge of diaphragm slab and decreasing the flexural stress with the aid of presenting additional vertical-resisting elements will improve the flexural capacity.

6) Method of strengthening strip wall footings. The foremost deficiencies typically came about in the footings are the excessive soil bearing pressure due to overturning forces and immoderate uplift conditions due to overturning forces. There are many techniques accessible for strengthening both deficiencies. Each technique has both benefits and disadvantages. A judgment should be made to select the satisfactory methods based totally on the present conditions.

a) Method of strengthening techniques for immoderate soil bearing pressure. The trouble of immoderate soil bearing stress prompted by using seismic overturning forces can be mitigated by increasing the bearing capability of the footing with the aid of underpinning the footing ends and supplying extra footing area Method of increasing the vertical ability of footing with the aid of adding new drilled piers adjacent and connected to the present footing. To furnish extra footing place or add new drilled piers could be high-priced and disruptive alternatives. An alternative of enhancing the existing soil properties by using injecting chemical grouts may want to be a better comparatively cheap technique.

b) Method of strengthening excessive uplift conditions. The excessive of uplift forces triggered by means of seismic overturning moments can be extended by increasing the uplift capability of the present footing by means of adding drilled piers or soil anchors. Providing substantial extend of uplift potential is most effective by including drilled piers or soil anchors. However, it needs to be referred to that all interior foundation works will be expensive and disruptive than exterior basis works.

7) Modification and reducing demand on existing building.

Many choices are available to limit the demand on current building. One of the easiest strategies is to reduce the weight of the building. This will minimize the earthquake load subjected to the building. Techniques that have been utilized to limit weight consist of removing the upper stories of a building, changing the use of the buildings, changing heavy roof system with mild assembly roof system, and getting rid of heavy appurtenance (such as parapets, balconies, water towers, or equipment). The more expensive technical method is via imparting supplemental damping and seismic isolator, to reduce building loading.

\section{Conclusion}

Based on our findings, the ground movement acceleration diagram generated from soil research information could be adopted to generate seismic vicinity mapping for Johor Bahru district. These seismic vicinity mappings allow researchers and engineers to realize locations that have more danger to be laid low with earthquake occurrence. The more crucial pre-cautions may be considered to mitigate the danger. To predict and simulate the actual earthquake loading, the fundamental records along with peak acceleration value (PGA) for seismic region mapping may be carried out via finite element structural analysis (FEA) tool.

\section{Acknowledgement}

All authors would like to thank Malaysia Public Works Department and Universiti Teknologi Malaysia (UTM) for aiding this research.

\section{References}

[1] A.A. Hendriyawan, M. Irsyam (2002), The Effect Of The Latest Sumatra Earthquake To Malaysian Peninsular, Journal Of Civil Engineering, Universiti Teknologi Malaysia, Vol. 15 No. 2

[2] R.S. Tung, W.Y.Leong, Processing Obstructive Sleep Apnea Syndrome (OSAS) Data, Journal of Biomedical Science and Engineering, 2012

[3] W.Y. Leong, J. Homer, D.P. Mandic. "An Implementation of Nonlinear Multiuser Detection in Rayleigh Fading Channel", EURASIP Journal on Wireless Communications and Networking (EURASIP JWCN), Vo;. 2006, pp. 1-9, Article ID. 45647, United States.

[4] W.Y. Leong, J.Homer, "Blind Multiuser Receiver in Rayleigh Fading Channel", Australian Communications Theory Workshop (AusCTW'05), pp.145-150, Brisbane, Qld, UQ, 2-4 Feb 2005.

[5] W.Y. Leong, D.P.Mandic, "Adaptive Blind Extraction for Postnonlinear mixed Signals", 2006 IEEE International Workshop on Machine Learning for Signal Processing (MLSP) Formerly the IEEE Workshop on Neural Networks for Signal Processing, pp. 9196, September 6-8, 2006, Maynooth, Ireland.

[6] P. E. Pinto, P. Franchin (2008) Assessing existing building with Eurocode 8 Part 3: a discussion with some proposals, pp.1-10.

[7] R.P.and H. Crowley (2009) Revisiting Eurocode 8 Formulae for Periods of Vibration and Their Employment in Linear Seismic Analysis, pp.1-14.

[8] National Center for Research on Earthquake Engineering, NCREE (2010) NCREE Newsletter, June 2010, Vol. 5, No. 2, pp.4-5.

[9] W.Y. Leong, Implementing Blind Source Separation in Signal Processing and Telecommunications, PhD Thesis, The University of Queensland, Australia, 2005.

[10] Lam and Chan (2018), "Design of Buildings and Structures in Low to Moderate Seismicity Region”, The Hong Kong Polytechnic University, pp.5-14. 